\title{
El sindicato hacia dentro. La relación entre la organización y los trabajadores desde el análisis de la afiliación
}

\author{
Pere Jódar
}

Universitat Pompeu Fabra

pere.jodar@upf.edu

\author{
Antonio Martín Artiles \\ Ramon de Alós-Moner \\ Universitat Autònoma de Barcelona \\ antonio.martin@uab.es \\ ramon.dealos@uab.es
}

\section{Resumen}

El presente artículo hace referencia a las principales transformaciones en el sistema productivo y en el empleo, y a sus efectos en el sindicalismo. El punto de partida adoptado son los tres interrogantes que plantea Hyman (1997), esto es, qué intereses representan los sindicatos; qué demandas acogen en sus tareas de representación, y qué métodos y procedimientos adoptan para esa finalidad. Estos interrogantes se contrastan con un estudio empírico sobre la afiliación al sindicato CCOO de Cataluña. El texto se estructura en tres partes. Ante todo, se presentan las principales características de los afiliados, que se relacionan con su posición en el mercado de trabajo, demandas y preferencias de acción colectiva y de organización del sindicato. La segunda parte destaca una tipología de la afiliación, construida a partir de combinar características personales, factores relacionados con la ocupación y otros sindicales; dicha tipología se relaciona con expectativas y preferencias de los afiliados, así como con sus prioridades para la acción sindical. Finalmente, se contrasta la teoría con los resultados obtenidos sobre prácticas organizativas y actitudes de los afiliados, y se enuncian algunas hipótesis y líneas de profundización para proseguir la investigación.

Palabras clave: sindicato, afiliación y tipología de los afiliados, segmentación del mercado de trabajo, compromiso, participación, contenidos de la acción colectiva, relaciones laborales, gobernanza.

Abstract. Looking inside the union. The relationship between the organisation and the workers from the analysis of the trade union members

This article refers to main changes in industrial system and workplaces and their effect on trade unionism. We take for this purpose the three questions suggested by Hyman (1997): whose interests trade unions represent, which issues they embraces for the task of representation, and what methods and procedures they adopt in understanding this task. These questions are contrasted with an empirical research carried out on the union members of $\mathrm{CCOO}$ of Catalonia. The text is structured in three parts. First, we present the main figures on membership related to labour market segmentation, demands and preferences on collective action and on trade union organisation. The second part emphasizes a typology of union members built combining personal features, features related to the occupation 
and others as union members; this typology is related with unions members' expectations and preferences, as well as with theirs priorities for union activity. Finally, we conclude contrasting the theory with our results on organisational practices and union members' attitudes, and we suggest some hypothesis to future researches.

Key words: trade union, union members and typology, labour market segmentation, commitment, participation, contents of collective action, industrial relations, governance.

\section{Sumario}

Introducción

1. La afiliación y los problemas organizativos de los sindicatos hoy

2. Composición de la afiliación y de la estructura organizativa del sindicato
3. Una tipología que agrupa diferencias entre los afiliados

4. Conclusiones y perspectivas de futuro Bibliografía

\section{Introducción}

El objetivo de este artículo es presentar datos que no son frecuentes en los estudios sindicales en nuestro país, cuya escasez de encuestas rigurosas sobre las relaciones laborales es preocupante. Desde hace unos cuantos años, hemos tenido la oportunidad de realizar un análisis detallado de la afiliación de un sindicato, CCOO de Cataluña, que ha facilitado el abordaje, aunque en forma de estudio de caso, de nuestro objetivo investigador ${ }^{1}$, que se ha enfocado hacia la adaptación de las formas organizativas y de acción colectiva del sindicato, de los afiliados y de los trabajadores, a los cambios productivos, laborales y ocupacionales actuales. El proyecto de análisis no ha finalizado y en su continuación plantea nuevas iniciativas no sólo sobre la afiliación, sino también sobre las características que adquieren las relaciones laborales en las empresas y los centros de trabajo. Hay que añadir también que, dentro de dicho proyecto, está en fase avanzada una nueva encuesta a delegados y otra a afiliados sobre la negociación, colectiva e individual, en los centros de trabajo.

Las páginas que siguen tratan sobre el interior de una asociación sindical y se ordenan en cuatro apartados. El primero esboza un breve marco teórico cuyo objetivo es describir una realidad y sugerir hipótesis futuras, y no tanto una explicación finalista; para ello utilizamos el esquema de Hyman (1997), que aborda tres preguntas esenciales para valorar la actual situación de transfor-

1. Este artículo se basa en el análisis de la encuesta a los afiliados a CCOO de Cataluña de diciembre de 1998 (123.440) realizada en colaboración con Fausto Miguélez y Óscar Rebollo; la muestra seleccionada fue de 1.112 personas (fracción de muestreo de 0,00901; nivel de confianza de 95,5\%; margen de error global de 3,056\%). El trabajo de campo se realizó durante los meses de enero a marzo de 1999, mediante entrevistas personales concertadas previamente por teléfono. El análisis y conclusiones del estudio se encuentran publicados en Alós y otros (2000). Sobre la primera encuesta a los afiliados de CCOO de Cataluña en 1992, ver Rebollo y otros (1993). 
mación: ¿a quién representa el sindicato?, ¿qué representa? y ¿cómo representa? El segundo apartado, presenta el panorama afiliativo del sindicato en cuestión, ordenado mediante estas preguntas y también comparando las dos iniciativas de encuesta de la afiliación realizadas hasta la fecha. El tercero aborda, con mayor énfasis analítico, la construcción de una tipología de los afiliados, que responde a unos criterios teóricos y supone una contrastación con la realidad. En el apartado conclusivo se argumenta de nuevo alrededor de las tres preguntas básicas enunciadas, sobre la base de esta tipología, revelando aciertos y problemas de la adaptación de la organización a las nuevas circunstancias; también se enuncian algunas hipótesis y líneas de profundización para proseguir la investigación.

\section{La afiliación y los problemas organizativos de los sindicatos hoy}

Desde la década de 1980 se habla con frecuencia de crisis del sindicalismo, a la par que de crisis o reestructuración económica y del mundo empresarial, o de crisis del Estado de bienestar, del fordismo o del trabajo. Abordemos la cuestión desde uno u otro de estos factores críticos, podemos concluir que algo está cambiando y seguramente sea la forma de interacción o de regulación de los elementos culturales, sociales, políticos y económicos que rodean al mundo del trabajo asentado a lo largo de la industrialización. Si las relaciones cambian, también se ven afectados los individuos, los grupos sociales y las formas asociativas de que se dotan para actuar en sociedad. Así, se sostiene que los sindicatos han perdido parte de su capacidad de representación e intermediación ante la transformación de la organización del trabajo, de la producción, de los productos y de los mercados, o ante las intervenciones desreguladoras de los gobiernos y la actitud hostil de los empresarios (ver Waddington y Hoffman, 2000; Miguélez y Prieto, 1991, 1999). Con todo, es importante no exagerar la extensión ni el grado de estas transformaciones; el taylorismo y el fordismo, también socavaron las bases del primer sindicalismo de oficio. En todo caso, afectan en distinto grado según la trayectoria de los distintos países europeos (Waddington y Hoffman, 2000). En este estado de cosas, nuestro objetivo no es el análisis de un sistema sindical nacional, ni tan sólo del conjunto de elementos internos y externos que influyen sobre la evolución de un sindicato. Nos vamos a centrar en la relación entre un sindicato y su afiliación en ese escenario de transformación, en el sentido de declive o de despliegue de nuevas formas de acción ${ }^{2}$.

2. Quedan fuera de este análisis, por ahora, cuestiones tan importantes como los efectos de la segmentación de los mercados laborales (Recio, 1999), de la diversidad de formas de trabajo y empleo (Supiot, 2001). Como, también, los problemas derivados de la negociación colectiva (Escudero, 2000) y su incidencia sobre la gobernabilidad de las organizaciones; en el caso sindical, entendida tanto como capacidad de unificar intereses y movilizar a los trabajadores en los objetivos de la organización, como de asegurar la coordinación de los procesos de negociación en los diversos ámbitos (Traxler, 1995). 
Organización formal (intereses propios)

\section{Sindicato}

- Estructura de toma de decisiones y de control sobre la base (incentivos funcionales y materiales)

Institucionalización de los mecanismos de representación (incentivos de identidad y sociabilidad)

Incentivos funcionales

\begin{tabular}{|c|c|}
\hline $\begin{array}{l}\text { Autoridad (eficacia) } \\
\text { Estrategias y reglas } \\
\text { de acción }\end{array}$ & \\
\hline & $\begin{array}{l}\text { Demandas e intereses } \\
\text { individuales y colectivos }\end{array}$ \\
\hline 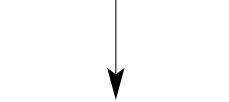 & $\begin{array}{l}\text { Incentivos materiales: } \\
\text { instrumentales, } \\
\text { sociales }\end{array}$ \\
\hline
\end{tabular}

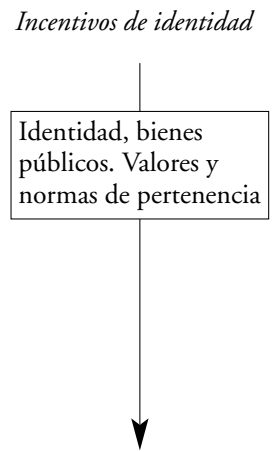

Incentivos de identidad

Afiliados

Representados, estructura de control desde la base
Participación (democracia) Apoyo, recursos, legitimidad

Incentivos de sociabilidad

Figura 1. El sindicato. Objetivos y funciones. Incentivos.

Fuente: Jódar (2000).

El punto de partida es un esquema de la relación entre sindicatos y afiliados que se basa en una reformulación de las propuestas de Streeck (1978) y de Hyman (1981) (figura 1). Las flechas del esquema, en la realidad del día a día sindical, van en los dos sentidos; aunque aquí sólo se representa el principal. Al esquema se puede incorporar el conjunto de incentivos propuesto por Wilson (citado en Lange y otros, 1991). Así, el sindicato aporta eficacia e identidad (la organización normativo-utilitarista de Etzioni) a la representación de las demandas e intereses de afiliados y trabajadores, obteniendo, a cambio de ello, apoyo, recursos y legitimidad. Por otra parte, las demandas e intereses pueden ser los de la propia organización y, por ello, a la eficacia (incentivos funcionales y materiales), se contrapone la participación como mecanismo de control de la base sobre la estructura dirigente (democracia e incentivos de sociabilidad e identidad). La identidad, las estrategias y las reglas de acción son, en principio, mecanismos de control de la cúpula sobre la base; pero no están exentos de contrapuntos, relacionados con los intereses materiales o de identidad (corporativos o solidarios) y con el grado de apoyo de las bases y de los trabajadores en general. El resultado de la interacción de estas dimensiones permite caracterizar el sindicato como una organización normativa social, en el sentido europeo continental, que no limita 
su acción de intermediación a la empresa, sino que la extiende al conjunto de la sociedad, y no sólo a aspectos económicos, sino también políticos y sociales (Gasparini, 1978). Es decir, una organización compleja de representación de intereses propios, de los afiliados y de los trabajadores, que aspira a ser voz de los representados, obteniendo su compromiso mediante la combinación de incentivos diferenciados: materiales (salarios, condiciones de trabajo), funcionales (limitan el control empresarial en la ocupación, en los derechos y las garantías laborales, etc.), de identidad (solidaridad), de sociabilidad (compensaciones no materiales por asociarse y pertenecer al grupo). Véase también Poole (1993: 36).

Hasta aquí tenemos un marco descriptivo de análisis, pero necesitamos un hilo ordenador. Hyman (1997) plantea tres preguntas muy simples para analizar los sindicatos: a quién representan (colectivos y grupos de trabajadores afiliados), qué representan (intereses y demandas que forman parte de la línea de acción sindical) y cómo representan (formas organizativas empleadas a los diferentes colectivos e intereses) (figura 2). De hecho, estas tres cuestiones implican todo un resumen de la teoría organizativa elaborada alrededor de los objetivos y las funciones de las asociaciones sindicales. El autor también apunta (traspasando el modelo de evolución social de Durkheim al cambio sindical) el análisis de las transformaciones del sindicato; desde un modelo tradicional de solidaridad mecánica («homogeneidad» de los asalariados, afiliación y sindicato "fordista»), hacia un modelo basado en la solidaridad orgánica (hetero-

1. A quién representan

Colectivos o segmentos de trabajadores

Élites

Centro

Periferia

Exclusión /

Hombres / Mujeres

Jóvenes / Maduros

Autóctonos / Emigrantes, etc.
2. Qué representan

Qué tipos de intereses y demandas

de los colectivos anteriores forman parte de los objetivos y las lineas de acción sindical

1. Salarios y condiciones de trabajo (materiales)

2. Estabilidad y seguridad en el trabajo / oportunidad de promoción (límites a la discrecionalidad empresarial) (funcionales)

3. Salario social (provisiones sociales, impuestos), política económica, mercado de trabajo (materiales)

4. Medio ambiente, consumo, comunidad local (existencia personal y social) (sociabilidad)

\section{Cómo representan}

Formas organizativas elegidas para representar a los colectivos $e$ intereses

Integración de intereses horizontal (inclusiva) o vertical (exclusiva)

Capacidades organizativas, para intervenir de forma estratégica y eficaz.

Democracia organizativa que requiere implicación y capacidad de decisión en los diferentes niveles (identidad)

Activismo organizativo en la gestión del descontento (identidad)

Figura 2. El esquema de Hyman para el análisis de las transformaciones del sindicato.

Fuente: basado en Hyman (1997). 
geneidad de los asalariados, afiliación y sindicato «posfordista») ${ }^{3}$. El modelo tradicional se basa en el obrero manual, empleado en empresas centrales con contrato estable y de jornada completa; que reproduce las desigualdades de poder entre asalariados, al priorizar las reivindicaciones económicas materiales y al confirmar el estatus de alienación y subordinación del trabajo dependiente. El modelo se enfrenta a retos que erosionan sus fundamentos; entre ellos la creciente diferenciación interna entre trabajadores, el aumento de la competitividad y la desregulación, el declive del igualitarismo, la flexibilidad del tiempo de trabajo; también a contradicciones entre la defensa de la seguridad del empleo (estabilidad) y la mayor necesidad de ocupabilidad centrada en la formación y la cualificación, o en el estímulo a la creación de ocupación; por último, la dificultad de ofrecer oportunidades individuales dentro de esquemas colectivos de acción. Para acometer estos retos, desde el punto de vista de la solidaridad orgánica, no sólo se trata de ampliar la base afiliativa (integración de la periferia y de los segmentos emergentes), sino, asimismo, de dotarse de un tipo de organización capaz de articular los diferentes niveles de decisión y las diferentes formas de acción y representación y, también, capaz de ampliar el diálogo social interno (Hyman, 1997).

A partir de nuestros estudios, podemos responder de manera bastante extensa a la primera de las preguntas ¿̇a quién representa?; también, de forma más limitada, a la segunda ¿qué representa el sindicato?, ya que se incorporan demandas y líneas de acción del sindicato y de sus afiliados, y, finalmente, al cómo representa, podemos argumentar desde dos líneas diferenciadas, aunque también limitadas: por una parte, la presencia real de unos u otros colectivos en los cargos organizativos, da una primera orientación, que se contrasta con las formas de acceso al sindicato y las formas de estabilización y permanencia de esos colectivos en el mismo; por otra parte, la participación de los distintos colectivos de afiliados y su valoración de los órganos de participación nos muestra el grado de implicación o distancia que mantienen.

Veamos dos escenarios con puntos de partida contrapuestos y que permiten visualizar las líneas de hipótesis anteriores. Hay un consenso bastante elevado en la literatura especializada sobre la fortaleza sindical en Alemania y la debilidad sindical en el Reino Unido, en la actualidad. Sin embargo, Streeck (2001) muestra los retos actuales del caso alemán, cuya fuerza histórica se basa en gran medida en el papel modélico de una federación (la del metal) y el convenio colectivo que negocia, cuyo objetivo es un escenario de igualdad rela-

3. Hyman quizá se arriesgue demasiado con la comparación, aunque la transposición de la idea de solidaridad mecánica y orgánica sintetiza bien el tipo de reto de conjunto al que están sometidos los diferentes sistemas sindicales. Habría que explorar las virtudes, no obstante, del esquema de Polanyi (los principios de comportamiento, como solidaridad, redistribución e intercambio, unidos a los modelos institucionales de simetría, redistribución y mercado), como en su momento hicieron Streeck y Schmitter (1985) añadiendo las asociaciones (sindicales, empresariales), aunque sin mencionar a este autor, tal y como remarca Cella (1997: 19). 
cionada con el intercambio de elevada productividad, por estabilidad, salario y pensiones elevadas. Y, no obstante, esa apuesta bajo el símbolo de la solidaridad (todos los asalariados con acceso a esas condiciones) está generando una profunda brecha entre los segmentos primarios y secundarios de los trabajadores. El autor apunta dos motivos principales: los servicios crecen y la productividad de los mismos no es comparable a la industrial, el segmento secundario aumenta de forma importante (no sólo por la incorporación de mujeres y jóvenes, sino también por la presencia de inmigrantes y, sobre todo, por la mano de obra de la Alemania del este con elevada tasa de paro). El escenario resultante es que el sindicato afilia a los trabajadores con mayor capacidad negociadora, y representa sus demandas e intereses mediante formas organizativas y de acción sindical tradicionales. De seguir las cosas así, los sindicatos alemanes tendrán dificultades de representación de los colectivos primarios emergentes (por la estructura y los contenidos de la negociación colectiva) y pueden divorciarse de los colectivos secundarios, relegados a un panorama de elevada precariedad y desocupación. El grave descenso de la afiliación, en fechas recientes, es un indicador de atención. Otro escenario es el británico; en ese país, los tres elementos críticos reseñados (reestructuración productiva, desregulación, actitud hostil de las empresas) actuaron de forma combinada, con un impacto neto en las tasas de afiliación y de cobertura de la negociación colectiva, que acusaron un descenso notorio durante las décadas de 1980 y 1990. Gallie, Penn y Rose (1996) concluyen, sin embargo, que la situación no ha debilitado el compromiso de los trabajadores con el sindicato. Es cierto que el sindicato se renueva en los segmentos primarios, ahora más bien asalariados no manuales de los servicios públicos, y tiene dificultades para llegar a mujeres, parados y precarios. Pero esas dificultades no se relacionan tanto con las actitudes de los trabajadores hacia sus asociaciones, como con sus condiciones de trabajo y ocupación. Si bien la renovación de demandas y de formas de organización y de acción destinadas a la integración de la periferia es limitada, los autores muestran que allá donde se han producido ha aumentado la influencia y la capacidad de acción de los sindicatos. La debilidad inicial del sindicalismo británico, tras los años Thatcher, puede ocultar un proceso de renovación. En el mismo sentido que los autores británicos y para el caso español, Polavieja (2003) muestra que no es tan importante para la implicación sindical (propensión a la afiliación, votación en las elecciones sindicales y participación en huelgas) el sexo o la edad, sino el tipo de contrato, una dimensión ajena al sindicato, sobre todo cuando estamos en pleno proceso de transformación de la misma. Los sindicatos nacen con la empresa y son reactivos a ellas, pero su reacción no tiene unos efectos inmediatos y más cuando el proceso de trabajo evoluciona tan dilatada y rápidamente como desde los años ochenta. No obstante las dificultades del estímulo externo, el sindicato ha de hacer constar en su agenda la renovación.

Una última cuestión del esquema propuesto es la de los incentivos, aquí la aportación será más limitada y descriptiva (ver tabla 11 y conclusiones); en este sentido, relevamos los diferentes incentivos propuestos, en qué momento 
parece actuar cada uno de ellos y qué colectivos parecen más motivados por unos y otros. En todo caso recordemos que las investigaciones de marcado carácter económico, o que siguen los modelos de acción colectiva de Olson (1992), acentúan los incentivos materiales como factor básico de la afiliación y del compromiso sindical. Desde la vertiente estructural, o la institucionalista (también Hirschman, 1977), en cambio, se introducen en el análisis los diferentes tipos de incentivos para intentar capturar sus pesos específicos; partiendo de la premisa que todos ellos intervienen en momentos diferentes, como en el de la formulación de las demandas o en el de la acción sindical para realizarlas. Véase, por ejemplo, Gallie (1996) para el Reino Unido, o Miguélez (1999) y el caso aquí relatado para España.

\section{Composición de la afiliación y de la estructura organizativa del sindicato}

\section{¿Quién está afiliado? (1992-1998)}

CCOO se ha consolidado como la primera fuerza sindical en Cataluña; también es el sindicato catalán con mayor número de inscritos, pese a que su tasa de afiliación en 1999 es un poco inferior al 6\% del conjunto de asalariados de Cataluña. El problema de la baja tasa de afiliación se aborda desde diversos ángulos internos y externos al sistema sindical, pero no es el objeto central de estas páginas, aunque sin duda de nuestro análisis se pueden derivar consecuencias. El retrato robot del sindicalista (tabla 1) no muestra a primera vista grandes variaciones sobre el tipo ideal tradicional, aquel designado por la literatura especializada como obrero fordista, hombre, mayor de 35 años, con bajo nivel de estudios, con contrato indefinido, con más de 10 años de antigüedad en la empresa, que trabaja a jornada completa en empresas de más de 100 trabajadores, como especialista no cualificado u oficial. Pero, incluso en estos trazos gruesos, encontramos dos variaciones importantes: el 55\% de los afiliados trabaja ahora en los servicios frente al $45 \%$ en la industria y la construcción; también, los afiliados de los servicios públicos se equiparan poco a poco a los de los servicios privados. La tabla 2 muestra la base masculina de la afiliación sindical. Es cierto que ha aumentado el número de mujeres en la composición de la afiliación a CCOO de Cataluña, pero su porcentaje del 28,6\% en 1998, está aún muy alejado del 40,2\% de mujeres asalariadas, siendo su proporción frente a los hombres afiliados de casi 1 a 3. Además, el fuerte aumento de la asalarización de las mujeres en años recientes da como resultado que su tasa de afiliación disminuya. Una dinámica similar a la de las mujeres caracteriza la trayectoria afiliativa de los más jóvenes (ver tabla 3). Por nivel de instrucción (tabla 4), la evolución de la composición de la afiliación muestra el aumento de los que tienen estudios superiores; pero también la sobrerrepresentación, acentuada con el paso del tiempo, de los colectivos con menor nivel de instrucción (sobre todo, sin estudios); y la infrarrepresentación de los afiliados con mayor nivel de estudios (sobre todo, medios). Sin embargo, en este caso la tasa 
Tabla 1. Características generales de la afiliación.

\begin{tabular}{llll}
\hline Edad & Hasta 29 años & $30-45$ años & $\begin{array}{l}\text { Más de 45 años } \\
43,5 \%\end{array}$ \\
\hline \multirow{2}{*}{ Sexo } & $12,3 \%$ & Mujeres & \\
& Hombres & $28,6 \%$ & \\
\hline \multirow{2}{*}{ Lugar de nacimiento } & Cataluña & Fuera de Cataluña & \\
& $59,3 \%$ & $40,7 \%$ & \\
\hline
\end{tabular}

Nivel de estudios Sin estudios o est. elementales Medios o superiores $53,2 \%$ $36,8 \%$

Tipo de contrato

Indefinido

$88,8 \%$

\section{Otros contratos}

$11,2 \%$

Antigüedad

en la empresa

Menos de 10 años

Más de 10 años

$40,7 \%$ $59,3 \%$

Relación con el empleo Jornada completa Jornada parcial Otras

Dimensión de la
empresa
Dimensión del centro
de trabajo
$77,9 \%$ $6,6 \%$ $15,5 \%$

Hasta 25 trab.

De 26 a 100

Más de 100

$11,8 \%$

$16,2 \%$

$72,0 \%$

Hasta 25 trab.

De 26 a 100

Más de 100

$48,4 \%$

$23,3 \%$ $28,3 \%$

Categoría profesional

No cualif./oficiales

Jefes/técnicos

Otras

$68,7 \%$

$17,0 \%$

$24,3 \%$

Sector económico

Industria y construcción

Servicios

$44,9 \%$

$55,1 \%$

Antigüedad de afiliación Menos de 4 años

De 4 a 10 años

Más de 10 años

$35,4 \%$ $29,4 \%$

$35,2 \%$

Fuente: Alós y otros, 2000.

Tabla 2. Composición por sexos de la afiliación a CCOO de Cataluña.

\begin{tabular}{llllll}
\hline & \multicolumn{2}{l}{ Total de afiliación } & \multicolumn{2}{c}{ Tasa de afiliación } & Asalariados ocupados \\
& $\mathbf{1 9 9 2}$ & $\mathbf{1 9 9 8}$ & $\mathbf{1 9 9 2}$ & $\mathbf{1 9 9 8}$ & en Cataluña, 1998 \\
\hline Hombres & $75,6 \%$ & $71,4 \%$ & $6,2 \%$ & $6,6 \%$ & $59,8 \%$ \\
\hline Mujeres & $24,4 \%$ & $28,6 \%$ & $4,0 \%$ & $3,7 \%$ & $40,2 \%$ \\
\hline \multicolumn{2}{l}{ Tasa de afiliación Cataluña } \\
\hline
\end{tabular}

Fuente: Alós y otros, 2000: 41. 
Tablas 3 y 4. Tasas de afiliación a CCOO de Cataluña.

\begin{tabular}{|c|c|c|c|c|}
\hline Edad (\%) & 1992 & \multicolumn{2}{|c|}{1998} & \\
\hline-25 años & 1,3 & \multicolumn{2}{|c|}{1,5} & \\
\hline $25-34$ & 5,8 & \multicolumn{2}{|c|}{4,1} & \\
\hline $35-44$ & 7,0 & \multicolumn{2}{|c|}{7,2} & \\
\hline $45-54$ & 6,8 & \multicolumn{2}{|c|}{8,1} & \\
\hline 55 y más & 5,8 & \multicolumn{2}{|c|}{5,4} & \\
\hline \multicolumn{2}{|c|}{ Nivel de instrucción (\%) } & \multicolumn{2}{|c|}{ Total de afiliación } & $\begin{array}{l}\text { Asalariados ocupados } \\
\text { en Cataluña, } 1998\end{array}$ \\
\hline \multicolumn{2}{|c|}{ Sin estudios } & 29,5 & 26,5 & 4,3 \\
\hline \multicolumn{2}{|c|}{ Elementales } & 33,4 & 36,6 & 21,1 \\
\hline \multicolumn{2}{|l|}{ Medios } & 28,5 & 24,0 & 56,2 \\
\hline \multicolumn{2}{|l|}{ Superiores } & 8,6 & 12,8 & 18,4 \\
\hline
\end{tabular}

Fuente: Alós y otros, 2000: 40.

de afiliación aumenta para todos los niveles, aunque es más significativa para los que no tienen estudios. Por tanto, existen problemas en la renovación generacional, de género y de nivel de instrucción. Pero en la comparación entre la encuesta de 1992 y la de 1998, también se detectan tendencias de cambio. Por ejemplo, la tradicional afiliación industrial da paso a una creciente presencia de asalariados de los servicios, lo que cambia el peso de las federaciones en el interior de la organización. Además, con relación a las federaciones industriales, en las de servicios hay mayor presencia de los inscritos con edades medias, las afiliadas (un 38,1\% de mujeres en los servicios frente a un 16,4\% en la industria), así como los niveles de estudio más altos o las categorías profesionales técnicas. Si observamos la ocupación de los afiliados, predomina claramente el sector primario dependiente; es decir, trabajadores con contrato indefinido, jornada completa, antigüedad dilatada en la empresa y baja autonomía en el trabajo; su presencia entre las dos fechas de encuesta aumenta, mientras disminuye el número de parados. Hay, no obstante, un leve incremento de asalariados a tiempo parcial, figura contractual que también ha aumentado durante la década de 1990 en el mercado de trabajo español. También, por categorías profesionales, disminuye notablemente la presencia de no cualificados y se incrementa un poco la de los técnicos. En resumen, el panorama sindical catalán no sólo se caracteriza por unas bajas tasas de afiliación, sino también por una estructura de afiliación desigual que parece reflejar las dicotomías al uso en las explicaciones del comportamiento sindical (trabajadores centrales / periféricos). No obstante, el sindicato se transforma para adaptarse al nuevo núcleo de trabajadores centrales, con empleo estable en los servicios ofrecidos por las grandes empresas públicas y privadas. Ahí, la diferencia entre géneros no son tan acusadas, y también se incrementa el peso de los asalariados no manuales, pero la adaptación organizativa alcanza poco a los precarios. 


\section{¿Cómo llegan al sindicato?}

Las vías de acceso de los trabajadores al sindicato son diversas, pero hay tres principales: la empresa, el sindicato y las redes sociales (tabla 5). La empresa es central en el reclutamiento de asociados; así, en torno al $80 \%$ de los afiliados son ocupados con empleo estable y jornada completa; además, la antigüedad en la empresa o la experiencia laboral consolidada también explican el acercamiento y la permanencia en el sindicato. Parece claro que en aquellas empresas más grandes, con convenio propio y de sector de actividad, se desarrolla con más garantías la acción sindical y la afiliación. Además, en el interior de estas empresas, son los trabajadores mejor situados, con mejores salarios y jornada y con más estabilidad, los que más se identifican con las tareas sindicales y traducen dicha identificación en compromiso. Éste es, seguramente, el tipo de trabajador que mejor puede apreciar la utilidad y la incidencia real del sindicato en su vivencia laboral cotidiana. Ahora bien, las redes sociales primarias también juegan su papel. De hecho, el $44 \%$ tienen, o han tenido, algún familiar afiliado a algún sindicato. Su papel es significativo para la construcción de la cultura sindical, ya que las redes sociales primarias actúan en el reclutamiento de manera inversamente proporcional a la fortaleza laboral de los afiliados en el mercado de trabajo. Cuanto menor es ésta última, más importancia tienen la familia y los amigos como forma de entrada y vínculo con el sindicato. Los afiliados reclutados a través de redes sociales se identifican con el polo más débil del universo sindical: trabajadores con pocos estudios, poco cualificados, con salarios bajos, con puestos de trabajo en la pequeña empresa y cierta rotación (cambio de actividad, empresa o contrato). Su trayectoria laboral más difícil se relaciona con una permanencia y un compromiso inestable y frágil; en conjunto se afilian más pero también se desafilian más. En resumen, cabe remarcar que tanto la actividad sindical en la empresa, como la influencia del entorno social próximo, son factores que explican la afiliación de forma más acentuada que, por ejemplo, la formación y los servicios sindicales. Pero la afiliación es, tanto dentro como fuera de la empresa, resultado de una relación entre personas y no sólo de una relación entre sindicato y trabajadores, o simples derivaciones de la elección racional.

Tabla 5. Forma de afiliación a CCOO (en \%).

Por medio de un compañero o compañera de la empresa 27,3

Mediante un amigo, familiar o vecino de fuera de la empresa

Tras hacer uso de algún servicio del sindicato

Después de la visita de algún representante del sindicato a la empresa 


\section{¿Por qué se afilian?}

En las encuestas analizadas aparecen dos conjuntos de motivos del porqué de la afiliación. El primero agrupa aquellas razones relacionadas con los incentivos de utilidad y funcionalidad del sindicato, un instrumento de defensa y de servicio a los trabajadores; especialmente esgrimidas por los trabajadores menos cualificados, los más jóvenes, las mujeres y los afiliados de inscripción más reciente; cuestiones que se relacionan con la necesidad de asesoramiento en problemas laborales y de protección ante las prácticas empresariales discrecionales. El segundo adquiere un carácter más ideológico o identitario; son los que responden que están afiliados porque todos los trabajadores deben estarlo. Lo que diferencia a este colectivo del anterior es la edad (mayor) y el sexo (hombres) o la mayor antigüedad en el sindicato. Estas motivaciones, no obstante, están relacionadas con el momento de reclutamiento e inscripción. La permanencia en el sindicato, en cambio, parece más cercana a la idea del sindicato como un instrumento útil y necesario para resolver problemas concretos del trabajo (78\% de los encuestados); así como con el alto grado de identificación de los afiliados con los responsables o líderes sindicales en la empresa ( $83 \%$ de los entrevistados), o con su forma de representar y de ejercer la acción colectiva. El sindicalismo nace con la empresa, se transforma con ella y también se revalida mediante la dinámica cotidiana entre afiliados y organización; cuestión, quizá, pero no necesariamente más acusada en el caso español (como en el anglosajón o japonés, por razones diferentes), que se da en los países del centro y del norte de Europa. La relación instrumental entre sindicato y afiliado tiende a hacerse más evidente en los colectivos con menores oportunidades ocupacionales y laborales, sin descuidar el incentivo de sociabilidad o la funcionalidad de la defensa frente a la empresa; mientras que, en proporción, los que tienen más estudios, los técnicos y los trabajadores del área pública, no están tan de acuerdo con el papel del sindicato como gestor de problemas concretos del trabajo; aunque no descuidan los incentivos materiales, ni tampoco los funcionales, en este caso relacionados con el control y la autonomía del trabajo, seguramente derivados de su mayor nivel educativo y de cualificación. Los servicios sindicales, a juzgar por las respuestas, se constituyen no tan sólo como un vehículo hacia la afiliación, sino que pueden jugar un papel en su estabilización; casi el 90\% de los entrevistados otorga mucha importancia a los servicios que ofrece el sindicato. Sin embargo, este porcentaje no se ajusta al grado real de utilización de los mismos (en el último año sólo el 40,5\% se han servido de ellos); aunque hay diferencias. Así, utilizan más los servicios del sindicato los colectivos con problemas ocupacionales y, comparativamente, los utilizan menos aquellos afiliados más estables (primarios). Pero, es más, son sobre todo los afiliados con rasgos secundarios los que utilizan en mayor medida los servicios jurídicos (más unidos a problemas laborales). La inclinación de estos colectivos hacia esos servicios parece reforzar una concepción más instrumental (que puede explicar la rotación de conjunto de la afiliación de estos grupos); aunque tampo- 
co debe descartarse la necesidad de obtener ayuda puntual en sus problemas laborales sin mayor compromiso sindical (incentivo funcional de defensa). En resumen, también en las razones de afiliación y permanencia en el sindicato se reproduce la diferencia entre los afiliados periféricos, más inclinados hacia factores de utilidad (incentivos materiales, incentivos funcionales), y los afiliados centrales, más inclinados hacia factores identitarios y funcionales; sin descuidar la utilidad que tienen más garantizada por su posición laboral. Esta disyuntiva se refuerza por el uso más acusado de ciertos servicios sindicales por los asalariados más frágiles. Los incentivos materiales están ahí, para todos, pero no se deduce una preeminencia de los mismos.

\section{Vieja y nueva afiliación. Estabilidad y fluctuación de los inscritos}

Los datos proporcionados por las encuestas aquí manejadas coinciden en dibujar un panorama que refleja serias dificultades para la consolidación de la afiliación sindical en el tiempo. En efecto, tanto en 1992 como en 1998 son muy numerosos los afiliados con menos de cuatro años en el sindicato (un $41,5 \%$ en 1992 y un $35,4 \%$ en 1998). En este panorama conviene fijar la atención sobre aspectos que nos parecen relevantes. En primer lugar, que la proporción de afiliados que pertenecen al sindicato desde antes de su legalización en 1977 es muy similar en ambas encuestas (un 13,7\% en 1992 y un $11,7 \%$ en 1998), pese a mediar entre ellas seis años; lo que indica que se trata de una organización joven, que conserva un porcentaje notorio de viejos militantes leales, con un papel significativo en la organización. Son los militantes del antifranquismo, protagonistas de la construcción del sindicato; son pocos y en relativa disminución, aunque con presencia notoria e influyente. En cambio, en la afiliación consolidada a lo largo del periodo democrático, hay un límite de crecimiento debido al fuerte impacto de la rotación afiliativa ${ }^{4}$; con dos vertientes diferenciadas: la afiliación flotante o intermitente y la rotación de entrada y salida, propia de los inscritos más recientes. En referencia a la afiliación flotante, más del 16\% de los afiliados habían estado antes en otro sindicato y, también, más del 16\% de los inscritos actuales perteneció a CCOO, se dio de baja y se reincorporó de nuevo. Se trata, sobre todo, del tradicional obrero fordista; hasta fechas recientes, núcleo duro de la afiliación. Su ir y venir sindical se puede explicar por su vinculación con el sindicalismo o la acción colectiva (y en ello puede influir un sistema de relaciones laborales que basa la representatividad en las elecciones sindicales y los organismos unitarios derivados), más que con un sindicato en concreto. De este modo, la decisión sobre la organización en la que inscribirse puede estar más condicionada por los planteamientos de uno u otro sindicato ante

4. Los datos sobre ficheros de afiliación que proporciona la organización apuntan también en esta dirección. Así, entre 1992 y 1999 se dan de alta en el sindicato 110.000 afiliados y, en el mismo periodo, se producen unas 100.000 bajas. Además, según los ficheros del propio sindicato, sólo el 45\% de los afiliados en 1999 lo estaban también en 1992. 
la negociación del convenio, o por la confianza generada por sus líderes más próximos, que por el ideario de un sindicato concreto. Ello no implica cuestionar la validez de los incentivos de identidad o sociabilidad, pero es bastante probable que funcionen a un doble nivel: más amplio y/o general en el sentido de una cultura sindical genérica, y mucho más ligados a personas (líderes) y prácticas concretas en las empresas para decidirse por uno u otro sindicato. Los afiliados con menos de dos años de antigüedad en la organización son, en términos comparativos, los más jóvenes: aunque un 13\% de los nuevos afiliados tienen 50 años o más. También las mujeres, sin diferencias muy significativas, se afilian en la actualidad más que los hombres; si bien permanecen, comparativamente, menos en el sindicato. Les afecta en mayor medida la rotación de entrada y salida de la afiliación, que muestra a ésta última como una opción coyuntural o frágil; se inscriben ante un problema laboral, permanecen durante un tiempo y después abandonan el sindicalismo. Un factor explicativo es el mayor riesgo de precariedad entre las mujeres o su situación laboral periférica, ya que la permanencia en el sindicato de las más estables es mayor. Asimismo, una de las diferencias más notables entre vieja y nueva afiliación es que, entre los afiliados recientes, la presencia de asalariados con estudios medios y superiores es mucho mayor que entre los más veteranos. $\mathrm{Si}$ introducimos el factor desocupación, destaca que el 30\% de los nuevos afiliados han experimentado el paro en los últimos cinco años, cifra que contrasta con la media del $20 \%$ para el total de la afiliación. Del mismo modo parece actuar la estabilidad en el contrato; así, mientras aproximadamente un $82 \%$ de los que tienen contrato indefinido llevan más de dos años en el sindicato, esa misma antigüedad sólo la ostentan el $49 \%$ de los que tienen otros tipos de contratos. Los colectivos más débiles laboralmente encuentran menos incentivos no sólo a la afiliación, sino también a la permanencia en el sindicato. La categoría profesional, agrupada en tres tipos diferentes (los técnicos, $10 \%$ de la afiliación total; los oficiales y jefes, 39\%; y 51\% el resto de categorías, sobre todo no cualificadas), también indica un cambio afiliativo siguiendo el vector tiempo de inscripción. Mientras un 25\% aproximadamente de los técnicos y no cualificados tienen menos de dos años de antigüedad en el sindicato, sólo el $15 \%$ de oficiales y jefes están en esta situación; por el contrario, la máxima antigüedad sindical (más de diez años) alcanza al 26\% de técnicos, al $30 \%$ de no cualificados y al $45 \%$ de oficiales. En resumen, los afiliados y afiliadas más recientes no cambian drásticamente el perfil de la afiliación del sindicato analizado; pero, en relación con el tradicional obrero fordista, están sobrerrepresentados, entre la afiliación reciente, dos tipos de trabajadores que se distinguen por su posición ante el trabajo y el empleo. Por una parte, los trabajadores más jóvenes, las mujeres, los empleados en pequeñas empresas, en servicios privados y, sobre todo, los colectivos que tienen mayor riesgo de paro y precariedad y, por otro lado, los técnicos y trabajadores con estudios superiores, empleados en grandes empresas de la industria privada y de los servicios públicos. Las diferencias entre ambos colectivos se centran en las dificultades de consolidar y estabilizar su afiliación. 


\section{La estructura de responsabilidad y dirección}

La estructura dirigente del sindicato, en un sentido amplio que agrupa a la responsabilidad (anterior o actual) en las empresas, en las federaciones o uniones territoriales y en los órganos centrales del sindicato, implica al 25\% de los afiliados; lo que se traduce en que una cuarta parte de los miembros de CCOO de Cataluña ha accedido a una u otra forma de poder y/o control (democracia). Ahora bien, sólo el $0,5 \%$ de los afiliados tiene o ha tenido responsabilidades orgánicas en los puestos de decisión claves del sindicato, y un 3,4\% en sus diversas estructuras. El principio democrático expuesto se enfrenta a las necesidades de eficacia y los caminos de acceso a cargos orgánicos tienen sus reglas. La conexión entre los dirigentes de la cúpula y los responsables sindicales en las empresas, representa el 2,9\% de afiliados que comparte responsabilidades en la empresa y en el interior de la organización. Sólo el 7\% de los afiliados con responsabilidad sindical acumulan dos o más cargos. Una respuesta indirecta a las formas de acceso a la responsabilidad nos la ofrecen las características personales, ocupacionales y sindicales de los actuales dirigentes (tabla 6). Así, la experiencia militante es uno de los caminos de acceso, puesto que son los afiliados más antiguos los que están más presentes en la estructura de dirección del sindicato; el 51\% de los afiliados con responsabilidad sindical acumulan más de diez años en el sindicato y, sin embargo, los inscritos antes de 1990 suponen menos del 35\% del total de la afiliación. Otro indicador es el tiempo de ejercicio de las tareas de responsabilidad sindical, entre los dirigentes de la estructura se detecta mayor renovación, mientras que entre los cargos de empresa, la responsabilidad se dilata más en el tiempo (aquí hay un núcleo duro con años de experiencia sindical y presencia en cargos). Precisamente entre este último colectivo (la mayor parte de ellos con tareas en el comité unitario), el responsable tipo es un hombre entre 35 y 50 años, casado, con nivel de instrucción bajo y afiliado antes de 1985; las mujeres, los jóvenes, las personas con cierto nivel de estudios, o los nuevos afiliados, en principio, sea por circunstancias propias (reticencias de los más cualificados o con estudios superiores) o por problemas reales de acceso y permanencia, están menos presentes en la estructura de cargos. También los trabajadores primarios acceden en mayor medida a la responsabilidad que los afiliados con características ocupacionales secundarias (ver tablas 6 y 7). En resumen, estas características perfilan también la doble trayectoria de implicación y asunción de responsabilidades sindicales en la empresa remarcada en la encuesta de 1992. La estructura del sindicato está confiada a los colectivos laborales con rasgos ocupacionales y profesionales tradicionales (excepto en la cúpula, donde predominan los emergentes primarios), mientras existen evidentes dificultades para captar los colectivos surgidos de la creciente segmentación y precariedad de los mercados laborales. Aunque estos colectivos se afilian al sindicato, su acceso a cargos de representación en la empresa es todavía limitado; bien por sus características ocupacionales y personales, bien porque el sindicato no ofrece estructuras de integración; en todo caso, esta dinámica se observa tanto en la coyuntura actual, 
Tabla 6. Perfil tipo del afiliado con responsabilidad sindical.

\section{Perfil tipo del afiliado con responsabilidad sindical}

\begin{tabular}{ll}
\hline Hombre & $79,0 \%$ \\
$35-49$ años & $56,5 \%$ \\
Casado & $70,0 \%$ \\
Bajo nivel de instrucción & $63,0 \%$ \\
Afiliado antes de 1985 & $46,3 \%$ \\
\hline
\end{tabular}

Colectivos suprarrepresentados

\begin{tabular}{lcc}
\hline Colectivo & \% s/ total afiliados & \% s/ total cargos \\
\hline Hombres & $71,4 \%$ & $79,0 \%$ \\
35-49 años & $46,6 \%$ & $56,5 \%$ \\
Afiliados antes de 1985 & $29,8 \%$ & $46,0 \%$ \\
\hline
\end{tabular}

Colectivos infrarrepresentados

\begin{tabular}{lcc}
\hline Colectivo & $\%$ s/ total afiliados & $\%$ s/ total cargos \\
\hline Mujeres & $28,6 \%$ & $21,0 \%$ \\
Menos de 35 años & $25,4 \%$ & $13,5 \%$ \\
Afiliados entre 1996 y 1999 & $29,8 \%$ & $13,5 \%$ \\
\hline
\end{tabular}

Fuente: Alós y otros, 2000.

como en la dinámica temporal de permanencia en los cargos de responsabilidad.

\section{La participación en el día a día de la vida sindical}

La participación en actividades sindicales está muy relacionada con el ámbito de la empresa, puesto que más del $50 \%$ de los afiliados prefieren ese nivel de implicación en la vida sindical. Por el contrario, la asistencia a actos o reuniones de carácter orgánico (en las uniones o federaciones) baja al 10\% o, incluso, menos. La comparación de las dos encuestas subraya que sólo se mantiene la participación en reuniones del sindicato en la empresa, en el resto de opciones disminuye la presencia de afiliados, especialmente en las reuniones convocadas por las uniones. Esta conclusión puede ser especialmente preocupante, bien porque es producto del cansancio de los afiliados, de los militantes y también de los dirigentes (los niveles intermedios incorporan ese riesgo), o bien porque el sindicato no consigue afianzar su voz alternativa ante los vertiginosos cambios en el entorno; tampoco se ha de descartar factores externos (elecciones sindicales, extensión de la negociación colectiva). Del mismo modo, por lo que respecta a la implicación, los colectivos nuevos (jóvenes, mujeres, nivel de 
Tabla 7. Afiliación por niveles de responsabilidad en CCOO de Cataluña.

\begin{tabular}{|c|c|c|c|c|c|}
\hline & & $\begin{array}{l}\text { \% sobre } \\
\text { cuadros } \\
\mathrm{CCOO}^{1} \\
(56)\end{array}$ & $\begin{array}{l}\text { \% sobre total } \\
\text { de núcleo } \\
\text { ampliado } \\
\text { cuadros } \\
\mathrm{CCOO}^{2} \\
(1.142)\end{array}$ & $\begin{array}{l}\% \text { sobre total } \\
\text { afiliados con } \\
\text { responsabilidad } \\
\text { empresa } \\
\text { y estructura }{ }^{3} \\
(28.993)\end{array}$ & $\begin{array}{l}\% \text { sobre total } \\
\text { afiliados } \\
\text { encuesta } \\
\text { CERES 19984 } \\
(116.436)\end{array}$ \\
\hline \multirow[t]{2}{*}{ Sexo } & Hombre & $80,4 \%$ & $76,5 \%$ & $79,3 \%$ & $71,4 \%$ \\
\hline & Mujer & $19,6 \%$ & $23,5 \%$ & $20,7 \%$ & $28,6 \%$ \\
\hline \multirow[t]{3}{*}{ Edad } & Menos de 35 & - & $8,6 \%$ & $13,5 \%$ & $25,4 \%$ \\
\hline & 35-49 años & $83,0 \%$ & $64,6 \%$ & $56,5 \%$ & $46,6 \%$ \\
\hline & 50 o más & $17,0 \%$ & $26,8 \%$ & $30,0 \%$ & $28,0 \%$ \\
\hline \multirow[t]{3}{*}{ Estudios } & Elementales & $21,9 \%$ & $44,1 \%$ & $38,2 \%$ & $36,6 \%$ \\
\hline & Medios & $34,4 \%$ & $38,2 \%$ & $28,2 \%$ & $24,0 \%$ \\
\hline & Superiores & $40,6 \%$ & $11,8 \%$ & $8,8 \%$ & $12,8 \%$ \\
\hline \multirow[t]{4}{*}{ Año afiliación } & Antes de 1985 & $87,5 \%$ & $48,1 \%$ & $46,3 \%$ & $29,8 \%$ \\
\hline & $1986-1991$ & $12,5 \%$ & $38,4 \%$ & $18,7 \%$ & $21,3 \%$ \\
\hline & $1992-1995$ & - & $12,5 \%$ & $19,1 \%$ & $19,1 \%$ \\
\hline & 1996-1999 & - & $0,2 \%$ & $16,0 \%$ & $29,8 \%$ \\
\hline
\end{tabular}

Notas: números entre paréntesis y cursiva, cantidad aproximada de afiliados en cada uno de los niveles:

1. Secretariado de CCOO de Cataluña y de las federaciones y uniones comarcales e intercomarcales; en total 56 personas. Fichero de cuadros, Secretaría de Organización de CCOO de Cataluña.

2. Miembros de los consejos, ejecutivas o secretariados de las federaciones, o de las uniones comarcales e intercomarcales (en total 1.142 personas). Fichero de cuadros, Secretaría de Organización de CCOO de Cataluña.

3. Afiliados con responsabilidades sindicales, según el resultado de la encuesta CERES 1998.

4. Características del total de afiliados a CCOO de Cataluña, extrapolando datos encuesta CERES 1998.

Fuente: Alós y otros, 2000.

estudios alto) y los afiliados con experiencias secundarias de trabajo, participan menos en las actividades sindicales que los colectivos tradicionales y los afiliados del segmento primario. Las principales dificultades para la participación son de tipo personal y responden a las características o necesidades individuales del afiliado o la afiliada; así, se argumenta que la participación y el ejercicio de cargos comporta una dedicación intensa que no todo el mundo puede o está dispuesto a asumir; le sigue la insuficiente preparación en materias tales como hablar en público, los conocimientos relacionados, etc. A mayor distancia hay dos factores que dependen más directamente de la organización; se trata de los horarios de celebración de las reuniones o la falta de informa- 
ción desde el sindicato sobre como participar. Por último, la opinión más negativa para el sindicato reside en el hecho que los cargos sindicales sean un grupo cerrado, aunque recibe un menor grado de acuerdo entre los entrevistados. En resumen, existen problemas de participación que revelan inadecuaciones de la estructura organizativa (información, formación). También, a grandes rasgos, se observa que son los colectivos de afiliación no tradicionales (mujeres, jóvenes, con estudios, profesiones cualificadas) o los que pertenecen al segmento ocupacional secundario (inestable), los que mantienen menor implicación o experiencia sindical y plantean dificultades hacia la participación relacionadas con el sindicato, mientras el resto aduce problemas más personales.

\section{La valoración de los órganos de representación}

Los afiliados afirman que la política sindical en la empresa se decide, sobre todo, en los organismos más cercanos a los trabajadores (comité de empresa y asamblea); cuestión reafirmada en ambas encuestas. Las instancias puramente sindicales parecen jugar un papel subsidiario. Aunque la pregunta no coincide exactamente con la de 1992, parece reforzarse el papel del comité de empresa, que consideran el órgano de defensa de los intereses de los trabajadores más adecuado, al tiempo que disminuye el papel desarrollado por la asamblea y el sindicato recibe una valoración similar. También incide el tipo y tamaño del centro de trabajo en esta cuestión, confirmando que la reticencia a la sindicalización y a la actividad sindical, en paralelo con la mayor presencia de la precariedad, tienen en la empresa privada de menos de 100 trabajadores un techo nítido. Valoran menos el comité y más la asamblea, en términos comparativos, los nuevos colectivos y los afiliados con características ocupacionales secundarias. En referencia a quien ejerce más influencia en la acción del comité de empresa, se observa, en las dos encuestas, que son los líderes sindicales. En resumen, se abren de nuevo las diferencias entre sectores tradicionales y nuevos; sobre todo porque jóvenes, mujeres, afiliados con estudios y trabajadores no estables sostienen en mayor medida que se tiene poco en cuenta la opinión de afiliados y trabajadores; también recogen este diagnóstico los afiliados a federaciones de servicios, los más recientes y los que no tienen cargos de representación en los centros de trabajo.

\section{Las demandas y la acción sindical}

La acción del sindicato, evaluada en su capacidad de hacer propuestas, su actitud ante la patronal y su capacidad de aumentar la participación de los trabajadores en la empresa, se valora positivamente (tabla 9). De la incidencia del sindicato sobre la sociedad, de sus demandas sociales, destacan el buen papel que estas organizaciones juegan en la defensa de la igualdad de oportunidades de las mujeres, en la mejora de la formación profesional o en la defensa del poder adquisitivo, pero no son tan optimistas con la intervención de los sindicatos en acciones destinadas a la reducción del paro y, en especial, del juvenil. 
Bajando al centro de trabajo, los ejes de acción sindical más valorados son aquéllos que tratan la salud laboral y la jornada, mientras que en los terrenos de la promoción o de las horas extraordinarias la valoración es menor. En referencia a las demandas preferentes de los afiliados, se observa que el 93\% está de acuerdo en repartir el trabajo; pero las demandas sobre los tiempos de trabajo se reducen a cuestiones concretas como elección de las vacaciones, compactación de la jornada semanal y flexibilización de la misma, en función de la adaptación de los horarios a las necesidades personales y familiares. Remarquemos que el 69\% afirma no realizar nunca horas extraordinarias. Los afiliados otorgan máxima prioridad a demandas como la estabilidad ocupacional, la salud laboral, la relación con los compañeros y el salario, mientras dan menor prioridad a la asunción de responsabilidades o a la moderación de las cargas de trabajo. En perspectiva de futuro, consideran más la acción contra la precariedad, la defensa del puesto de trabajo, la no discriminación por razones de sexo o etnia y la salud laboral; en cambio, son menos reseñados el control de la innovación tecnológica o la reducción de jornada. En resumen, hasta aquí no aparecen distancias significativas entre características de los afiliados y demandas y formas de acción.

\section{Una tipología que agrupa diferencias entre los afiliados}

Las páginas anteriores muestran una estabilidad notoria de las características de la afiliación, aunque también síntomas de cambio. Por este motivo se recurrió a la elaboración de una tipología que agrupa elementos transversales. Su base de diseño son algunas hipótesis relevantes sobre la afiliación sindical y, también, algunas transformaciones en las características del trabajo y del empleo, que condujeron a seleccionar tres conjuntos de factores destinados a distinguir distintos tipos de afiliados: factores individuales, como el género, la edad y el nivel de estudios; factores relacionados con la ocupación, como la categoría laboral, el sector de actividad, el tamaño de la empresa y del centro de trabajo, las condiciones de trabajo (aquí, básicamente el salario, puesto que el impacto de la contratación se desvirtúa ante el $90 \%$ de afiliados estables); finalmente, un factor puramente sindical como es la antigüedad en la organización. La combinación de estos tres conjuntos de factores permite observar seis grandes tipologías de afiliados, que se han identificado a partir de sus rasgos dominantes como: los tradicionales, los emergentes, los jóvenes, las mujeres, los parados y los jubilados; aunque, debido a su peso específico bajo (poco más del $7 \%$ cada uno de ellos), no trataremos aquí a estos dos últimos. Las características y proyección gráfica de las categorías (y grupos) se muestran en el gráfico 1 y tabla 8 , respectivamente 5 .

5. Para probar la consistencia de esta tipología, se ha procedido a un análisis de correspondencias múltiples (excluyendo a parados y jubilados) que ha permitido relevar tres dimensiones que explican el $93 \%$ de la relación conjunta de las variables o inercia. La primera explica la mayor parte de la inercia, el 52\%, e incorpora estratificación, antigüedad y sexo; es decir, en un polo están los varones adultos, con ingresos y cualificaciones medias, así 


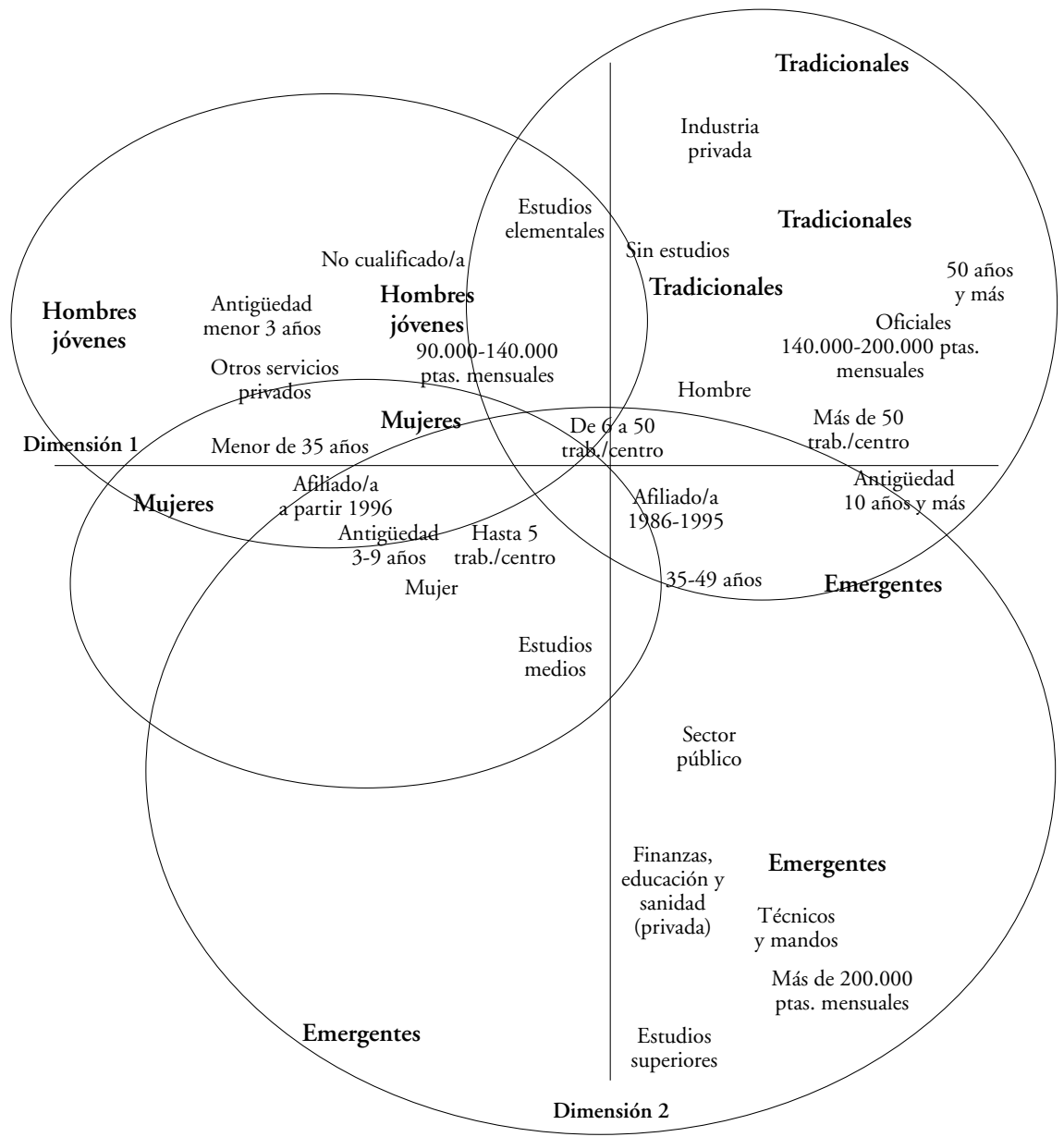

Gráfico 1. Proyección de las categorías y los grupos (de ocupados/as) sobre las dimensiones. La posición de las categorías y de los grupos no es exacta sino aproximada, a fin de facilitar su visualización. En el gráfico se proyectan únicamente las dos primeras dimensiones de las tres extraídas en el análisis (el solapamiento parcial entre los grupos «Hombres jóvenes» y «Mujeres» se debe a que éstos se diferencian sobre todo con relación a la tercera dimensión).

como los que llevan más tiempo en la empresa —en centros de mayor tamaño- y en el sindicato, mientras que, en el polo opuesto, tenemos los jóvenes y las mujeres, con ingresos y cualificaciones bajas y con menor antigüedad en la empresa y en la afiliación. La segunda explica el $30 \%$ de la inercia total; se define por variables relacionadas con las exigencias del trabajo y permite distinguir entre aquéllos con mayor nivel educativo, cualificación e ingresos (que, a su vez, trabajan en mayor medida en el sector público y en servicios cualificados) del resto de los afiliados. La tercera explica mucho menos, el $11 \%$, pero tiene su eje en el sector que diferencia claramente el ámbito de los servicios cualificados de los no cualificados; en menor medida, en esta dimensión, el sexo adquiere una cierta importancia. 
Tabla 8. Caracterización de la tipología de la afiliación.

\begin{tabular}{|c|c|c|c|c|c|c|c|}
\hline & Tradicionales & Emergentes & Jóvenes & Mujeres & Parados & Jubilados & Total \\
\hline Porcentaje sobre total & 24,9 & 24,9 & 17,2 & 17,8 & 7,3 & 8,0 & 100,0 \\
\hline $\begin{array}{l}\text { Relación con actividad } \\
\text { Ocupado/a } \\
\text { Parado/a } \\
\text { Jubilado/a o pensionista }\end{array}$ & 100,0 & 100,0 & 100,0 & 100,0 & 100,0 & 100,0 & $\begin{array}{r}84,7 \\
7,3 \\
8,0\end{array}$ \\
\hline
\end{tabular}

\begin{tabular}{|c|c|c|c|c|c|c|c|}
\hline \multicolumn{8}{|l|}{ Edad } \\
\hline$<35$ años & 6,5 & 20,9 & 80,8 & 13,4 & 29,1 & 4,7 & 25,4 \\
\hline 35-49 años & 50,3 & 65,2 & 15,1 & 67,0 & 38,4 & 6,7 & 46,6 \\
\hline$>49$ años & 43,1 & 13,9 & 4,1 & 19,6 & 32,5 & 88,6 & 28,0 \\
\hline \multicolumn{8}{|l|}{ Sexo } \\
\hline Hombre & 91,2 & 71,5 & 89,2 & 31,9 & 52,5 & 78,8 & 71,4 \\
\hline Mujer & 8,8 & 28,5 & 10,8 & 68,1 & 47,5 & 21,2 & 28,6 \\
\hline \multicolumn{8}{|l|}{ Nivel de estudios } \\
\hline Sin estudios & 34,1 & 5,5 & 16,5 & 39,0 & 38,1 & 49,8 & 26,5 \\
\hline Estudios elementales & 54,8 & 9,8 & 42,2 & 46,9 & 28,1 & 36,1 & 36,6 \\
\hline Estudios medios & 10,3 & 44,2 & 38,0 & 8,3 & 23,9 & 10,7 & 24,0 \\
\hline Estudios superiores & 0,8 & 40,6 & 3,4 & 5,8 & 9,8 & 3,3 & 12,8 \\
\hline \multicolumn{8}{|l|}{ Ingreso mensual neto } \\
\hline$<90.000$ & 0,4 & 1,1 & 9,6 & 28,5 & 59,2 & 46,2 & 15,3 \\
\hline $90-140.000$ & 26,7 & 13,0 & 43,3 & 60,7 & 33,9 & 19,9 & 32,6 \\
\hline $140-200.000$ & 67,1 & 36,7 & 44,8 & 7,8 & 6,9 & 27,7 & 37,3 \\
\hline$>200.000$ & 5,7 & 49,1 & 2,3 & 3,1 & 0,0 & 6,2 & 14,8 \\
\hline \multicolumn{8}{|l|}{ Categoría laboral } \\
\hline No cualificado/a & 21,4 & 6,9 & 43,8 & 45,3 & 33,0 & 25,0 & 26,9 \\
\hline Oficial & 59,9 & 24,3 & 27,9 & 5,6 & 29,8 & 37,7 & 31,8 \\
\hline Técnico/a & 3,2 & 45,2 & 10,9 & 7,0 & 8,9 & 16,0 & 17,0 \\
\hline Otra o ninguna categoría* & 15,5 & 23,6 & 17,4 & 42,1 & 28,3 & 21,3 & 24,3 \\
\hline \multicolumn{8}{|l|}{ Año última afiliación } \\
\hline Antes de 1986 & 48,2 & 24,3 & 1,1 & 28,7 & 26,0 & 60,7 & 29,8 \\
\hline Entre 1986 y 1995 & 40,7 & 45,8 & 27,7 & 49,9 & 44,0 & 25,5 & 40,5 \\
\hline Después de 1995 & 11,1 & 30,0 & 71,2 & 21,4 & 30,1 & 13,8 & 29,8 \\
\hline \multicolumn{8}{|l|}{ Antigüedad en la empresa } \\
\hline$<3$ años & 5,1 & 6,5 & 46,6 & 13,7 & - & - & 15,7 \\
\hline 3-9 años & 9,9 & 23,5 & 45,5 & 28,8 & - & - & 25,0 \\
\hline$>9$ años & 85,1 & 70,1 & 7,9 & 57,5 & - & - & 59,2 \\
\hline \multicolumn{8}{|l|}{ Sector de actividad } \\
\hline Sector público & 14,0 & 50,3 & 8,0 & 36,3 & - & - & 28,4 \\
\hline Industria privada & 74,5 & 11,5 & 66,2 & 12,4 & - & - & 40,5 \\
\hline Servicios privados «cualificados» & 0,8 & 32,0 & 7,6 & 2,5 & - & - & 11,8 \\
\hline Otros servicios privados & 10,8 & 6,2 & 18,2 & 48,8 & - & - & 18,9 \\
\hline \multicolumn{8}{|c|}{ Tamaño del centro de trabajo } \\
\hline$<6$ trabajadores & 13,4 & 25,8 & 15,9 & 54,0 & - & - & 25,7 \\
\hline 6-50 trabajadores & 34,2 & 37,5 & 45,7 & 25,7 & - & - & 35,9 \\
\hline$>50$ trabajadores & 52,3 & 36,7 & 38,5 & 20,3 & - & - & 38,4 \\
\hline
\end{tabular}

* Categoría no incluida en el análisis.

Fuente: Encuesta CERES 1998. 
Tabla 9. Algunas características de la acción sindical según los afiliados (en \%).

Tipo de convenio

Centro de trabajo

Sector o ramo

Funcionario

No hay convenio

Lo desconoce

\section{Actitud empresa}

Contraria sindicatos

Acepta, pero no colabora

Busca colaboración

\section{Salario neto mensual}

Hasta 90.000

De 90.001 a 140.000

De 141.001 a 200.000

Más de 200.000

Más de 300.000

\section{Cambiar la organización del trabajo}

22,8 No es posible

37,2 Cambios pequeños

34,3

12,3 Sí, es posible

40,0

2,3 Grado de autonomía sobre horario y jornada

15,4 elevado

Determinar inicio y fin jornada

13,1 Adaptación horario a necesidades

36,5 fam. y person. 27,6

30,0 Elegir momento y distribución vacaciones 22,7

Autonomía en realización funciones de trabajo

13,0 Sin margen, ejecuta órdenes

32,6 Decide, pero los procedimientos

37,3 son muy rígidos

11,9 Decide, sobre directivas generales

2,8 establecidas

Tiene autonomía

39,2

\section{Acuerdo con:}

sobre las siguientes cuestiones

Coherencia de la acción sindical

Capacidad de hacer propuestas

Actitud ante la patronal

51,8 El reparto del trabajo

51,6 Reducir la jornada resta competitividad 15,7

49,4 Valoración positiva de la acción sindical actual en

47,5 la empresa sobre las siguientes cuestiones:

Seguridad e higiene

Afiliados que dan máxima prioridad $(9,10)$ a:

Estabilidad puesto de trabajo

60,1 Jornada y vacaciones

39,3

58,3 Formación profesional

35,5

52,9 Contratación temporal $\quad 34,9$

Buena relación con los compañeros

48,7 Salarios

34,0

39,5 Ascensos y promoción 30,0

Relación dirección - trabajadores

Posibilidades de realización personal

Horario de trabajo

32,5

29,9

Contenido de las tareas

29,3

Autonomía en la organización del trabajo

28,7

Posibilidades de promoción

Distancia desde el domicilio

Posibilidades de asumir responsabilidades

Carga de trabajo moderada

Reivindicaciones prioritarias en el futuro

(señalan muy importante)

Lucha contra la precariedad

Defensa puesto de trabajo

No discriminación de sexo o étnica

Mejora salud laboral

Formación y reciclaje

Reducción diferencias salariales

Incrementos salariales

Control innovación tecnológica

Horas extra

28,0

27,9

25,0

21,7

18,6

Preferencias sobre jornada laboral (muy prioritario)

Elegir momento y distribución vacaciones $\quad 39,2$

Horario adaptado necesidades

famil. y personal.

32,4

Menos días de trabajo en la semana $\quad 30,0$

Margen para fijar inicio y fin jornada $\quad 28,2$

Jornada más compactada (menos pausas) $\quad 19,0$
71,7

70,9

68,3

66,9

56,5

51,6

50,6

46,8

40,8
Reducción jornada

\section{Realización horas extraordinarias}

Regularmente cada día $\quad 7,9$

Regularmente, fines de semana $\quad 3,2$

De vez en cuando 20,2

Nunca 68,7

Preferencias sobre jornada laboral (muy prior.)

Reducir jornada y salario $\quad 18,0$

Trabajar más horas y ganar más $\quad 16,5$ 
Tabla 9. Algunas características de la acción sindical según los afiliados (en \%) (continuación).

\begin{tabular}{lc}
\hline Valoración positiva de la acción sindical en la sociedad \\
Igualdad de oportunidades mujeres & 64,2 \\
Mejor formación profesional & 62,8 \\
Defensa poder adquisitivo & 58,1 \\
Mejora servicios públicos & 57,9 \\
Integración trabajadores extranjeros & 55,2 \\
Mejora contratación precaria & 52,6 \\
Justicia fiscal & 52,6 \\
Reducción del paro & 40,6 \\
Reducción paro juvenil & 40,0 \\
\hline
\end{tabular}

Fuente: Alós y otros, 2000, capítulos 2 y 4.

Los «tradicionales» (25\% de los inscritos) son los afiliados típicos del período de mayor auge del sindicalismo; trabajan en la industria, en empresas medianas y grandes y pertenecen al segmento primario dependiente; en términos de categoría profesional son, sobre todo, oficiales, con contrato estable y nivel de estudios elemental. Casi en su totalidad son hombres (91\%), de edades medias y elevadas. Su nivel de ingresos es medio (en algunos casos, alto), en gran parte debido a la antigüedad en la empresa y a la negociación colectiva. Con todo, no cabe olvidar el descenso de afiliados en este grupo, debido a las reestructuraciones y cierres de empresas, con salidas hacia el paro o la jubilación anticipada. Su antigüedad en el sindicato es alta (48\% inscritos antes de 1986); también son los que, en proporción, se han afiliado en mayor medida a otros sindicatos o se han inscrito de nuevo a CCOO (afiliación flotante).

Los «emergentes» (25\% de la afiliación), pueden ser el grupo predominante en el próximo futuro sindical (los nuevos trabajadores centrales de la sociedad posindustrial). Es un colectivo más equilibrado en términos de género, porque refleja la misma proporción que adquieren los dos sexos en el mercado de trabajo; además, trabajan en ámbitos en los que el empleo femenino crece y en el que gana terreno a los hombres. Se caracteriza por la estabilidad laboral, de hecho la mitad trabaja en el área pública y un tercio, en servicios privados cualificados (grandes empresas financieras y del transporte, sanidad y enseñanza); a diferencia del grupo anterior, se hallan en sectores en expansión o consolidados. Su nivel de estudios, categoría laboral y salarios son más altos; son asalariados no manuales. Predomina la franja de edad media (35-49 años), si bien más de una quinta parte son jóvenes. Aunque una cuarta parte de este colectivo está afiliado antes de 1986, es un grupo de mayor crecimiento afiliativo que el primero - el 30\% afiliado después del 1995, frente al 11\% de tradicionales-, pero no es el que crece en mayor proporción.

Los «hombres jóvenes» (17\% de los inscritos) también lo son en términos sindicales: el $71 \%$ de los mismos se ha afiliado después de 1995 y en su tota- 
Tabla 10. ¿A quién representa el sindicato?

\begin{tabular}{lll}
\hline Núcleo central & Tradicionales (25\%) & Emergentes (25\%) \\
\hline Sector económico & Industria & Servicios \\
Tipo empresa & Mediana, grande, privada & Grande, pública y privada \\
Tipo de trabajo & Manual & No manual \\
Categoría & Oficiales & Altas y técnicas \\
Sexo & Hombres & Hombres/mujeres (-) \\
Edad & Edad madura & Edad media \\
Estudios & Elementales & Medios/altos \\
Contratación & Estabilidad & Estabilidad \\
Antigüedad empresa & Alta & Alta \\
Salario & Salarios medios & Salarios altos \\
Regulación condiciones trabajad. & Neg. colectiva central & Neg. colectiva central \\
\hline & & \\
Periferia & Hombres jóvenes (17\%) & Mujeres (18\%) \\
\hline Sector económico & Industria y servicios & Servicios \\
Tipo empresa & Pequeña & Pequeña, pública y privada \\
Tipo de trabajo & Manual y no manual & No manual \\
Categoría & Bajas, subocupación & Bajas, no cualificados \\
Sexo & Hombres & Mujeres/hombres (-) \\
Edad & Jóvenes & Media \\
Estudios & Medios & Bajos \\
Contratación & Menor estabilidad & Estabilidad \\
Antigüedad empresa & Media/baja & Alta \\
Salario & Medios & Bajos \\
Regulación condiciones trabajad. & Periferia NC & Periferia NC \\
\hline & & Jubilados 8\% \\
Otros & Desocupados (7\%) & Hombres (provienen \\
\hline & Mujeres & de los tradicionales) \\
\hline & No cualificados & \\
\hline & & \\
\hline
\end{tabular}

lidad, después de 1986. Puede influir en esta dinámica la edad, pero quizá más la inestabilidad de su trayectoria laboral; con cambios de un sector a otro, de una empresa a otra ( $50 \%$ con menos de 3 años en la empresa), contratos no estables, etc. Sus dos características fundamentales son la juventud ( $81 \%$ por debajo de los 35 años) y ser casi todos hombres (89\%). Otro rasgo clave —relacionado con la inestabilidad - es el sector de actividad en el que trabajan, la industria de pequeño tamaño (y, en menor medida, los servicios privados no cualificados). En otros aspectos mantienen posiciones medias, por ejemplo en sus niveles de estudio o en sus ingresos; mientras que la categoría laboral tiende a ser baja y relacionada con la subocupación funcional. Su posición es débil; y no sólo ante la ocupación, sino también en el sindicato, porque aunque es el grupo que en proporción crece más en los últimos años, su situación laboral hace inestable y frágil su afiliación.

Las «mujeres» (18\% de la afiliación) no incorporan sólo a asalariadas, pero sí es el grupo en el que éstas tienen una mayor presencia. Las mujeres consti- 
tuyen el $68 \%$ de ese colectivo y casi triplican la presencia femenina en el mercado de trabajo. Predominan las edades medias y los estudios relativamente bajos, también los ingresos y las categorías inferiores. Varios de estos rasgos se corresponden con el hecho de trabajar en servicios privados poco cualificados (casi el 49\%); aunque el 36\% está en el sector público, probablemente en los escalones más bajos de categoría y salarios. Esta última razón junto con la edad media del colectivo se relacionan con la elevada antigüedad en sus empresas y su estabilidad ocupacional. La antigüedad afiliativa es media, semejante a la del tipo emergente. Su posición en el sindicato es bastante débil por varios motivos: por el tipo de empresa y tareas en las que trabajan y por la dificultad de compaginar la vida sindical y la doble presencia laboral y doméstica.

Respecto a la llegada y permanencia en el sindicato, los tradicionales son los menos fieles a él, aunque no al sindicalismo, puesto que son los que en mayor proporción han estado afiliados a otros sindicatos y los que más se han «desafiliado» y «reafiliado» a CCOO; también son quienes más se han afiliado por iniciativa propia, junto con los emergentes; mientras que los jóvenes lo han hecho más por influencia de compañeros de trabajo y las mujeres, por influencia de redes sociales. Las diferencias en la vía de entrada no implican una identificación divergente con los valores que defiende el sindicato, ni con las actividades que lleva a cabo o con la importancia que tienen los servicios que ofrece. El grado de identificación con el sindicato es bastante alto y semejante en todos los grupos; todos creen mayoritariamente que resuelve problemas y que sus líderes merecen confianza.

En la asunción de responsabilidades, los tradicionales son los que más acumulan en el interior de la organización (un 38,4\%), seguidos de los emergentes $(24,5 \%)$ y de las mujeres $(21,6 \%)$. Las diferencias son muy notorias, sobre todo en términos de empresa (ser delegado o delegada), pero lo son también en términos territoriales (uniones locales, comarcales), aunque menos en términos sectoriales. En otras palabras, los tradicionales siguen dirigiendo el sindicato muy por encima del peso que tiene su afiliación, mientras que el resto (en particular los jóvenes) está muy por debajo. También se puede contrastar la composición de la «cúpula» de CCOO de Cataluña, la ejecutiva, en términos de la tipología aquí utilizada. Ahí, los emergentes van ocupando el lugar que tenían los tradicionales. La media de edad del colectivo dirigente es de 45 años, predominan los hombres $(80 \%)$ por encima de la distribución de la afiliación por sexo; el nivel de estudios es medio-alto, y el ramo de procedencia es el indicador más determinante, más del $50 \%$ de la cúpula procede de los ramos del grupo emergente y un $34 \%$, de los ramos tradicionales. El resto de tipos no tiene apenas presencia.

En referencia a la participación, los tradicionales son más participativos que los demás —aunque sin grandes diferencias-, tanto en las asambleas de trabajadores como en las reuniones del sindicato a todos los niveles. Una vez más, aquí los jóvenes quedan fuertemente atrás, quizá porque las formas de participación no son las adecuadas a su situación laboral ni a sus expectativas. Entre las dificultades a la participación, la más importante, e indicada por 
todos los grupos, es el tiempo que exige; en la consideración del sindicato como grupo cerrado son los jóvenes y los emergentes los que ponen más el acento que el resto, pero sin diferencias concluyentes. Y, en cuanto a la valoración de los órganos de representación, los tradicionales valoran más el comité de empresa como organismo adecuado para conseguir sus demandas, mientras que los emergentes tienen más confianza en la asamblea de trabajadores y en el propio sindicato, por este orden. Los otros grupos quedan en una posición media.

Se puede afirmar que, en general, hay un elevado grado de acuerdo entre las tipologías de tradicionales, emergentes, mujeres y jóvenes sobre la actuación actual del sindicato en las cuestiones que preocupan a los trabajadores (demandas e intereses). Pero hay algunas diferencias. Los emergentes, a pesar de tener unas características que les hace más proclives a la realización de horas extraordinarias, son los más críticos con la actuación del sindicato ante las mismas; en cuanto a la formación profesional, las más críticas con la acción sindical son las mujeres, mientras que emergentes y jóvenes remarcan menor eficacia en la cuestión de ascensos y promociones, y los tradicionales en el ámbito de la seguridad e higiene. En general, son los periféricos, los jóvenes y las mujeres los que mejor valoran la acción sindical contra la precariedad. Concretamente, la tipología de mujeres muestra mayor satisfacción con la acción sindical en conjunto, excepto en lo que se refiere a la igualdad de oportunidades. Esta valoración sobre el ejercicio del sindicato como portavoz de demandas se corresponde con la opinión, compartida por los diferentes tipos relevados, de que el sindicato es coherente en su línea de acción y propicia la participación y la consulta de los trabajadores. No obstante, jóvenes, emergentes y mujeres son más críticos que los tradicionales respecto a la capacidad del sindicato de proponer nuevas líneas de acción o demandas de futuro. Asimismo, los jóvenes son más críticos con la actitud del sindicato ante la patronal, mientras que los tradicionales están más preocupados por los incrementos y las diferencias salariales, y los emergentes visan como prioridades la reducción de la jornada y el aumento de las vacaciones. Los más estables se preocupan más por la lucha contra la precariedad, la formación y el reciclaje; los tradicionales y jóvenes reclaman mejoras en seguridad e higiene.

En resumen, los tradicionales han dado cuerpo a la organización, a sus líneas de acción y de demanda, a sus formas de participación; su base de acción es el conflicto y la negociación colectiva y sus demandas son el salario, la reducción de la jornada laboral y la intervención en la organización del trabajo; centrados en la ocupación, sus actitudes condicionan las visiones alternativas sobre el trabajo (que incluyan las cargas reproductivas o la separación de los tiempos, por ejemplo), necesarias para afrontar los actuales retos sindicales. Los emergentes, introducidos más recientemente en el sindicato, tienen mayores oportunidades de negociación individual, aunque se sumen a la acción colectiva; están más interesados en cambios organizativos que aumenten su participación y autonomía en el trabajo y les preocupa la distribución de los tiempos o su nivel de cualificación (formación, promoción). Los jóvenes supo- 
nen un reto con diversas facetas; si su situación laboral es tan transitoria como la edad, antes o después alcanzarán cierta estabilidad y se incorporarán al sindicato, entre los tradicionales o entre los emergentes; pero si la situación laboral se prolonga en forma precaria, la consolidación de su afiliación dependerá de cambios organizativos profundos y de estrategias de demanda y acción específicas. Las mujeres también plantean un reto importante, ya que por su baja cualificación laboral, nivel de estudios bajos, bajos salarios (que les separan de los colectivos de mujeres emergentes) y presencia en pequeñas empresas de servicios privados, tienen una capacidad de acción débil; también son un colectivo de difícil acceso y consolidación en el interior del sindicalismo actual.

\section{Conclusiones y perspectivas de futuro}

Dividiremos estas conclusiones en relación con el hilo conductor de este artículo; que son, las características de la afiliación, la representación de intereses y la acción sindical y la estructura organizativa y de participación del sindicato. La afiliación se compone en un $50 \%$ por trabajadores primarios y un $50 \%$ de secundarios; entre los primarios, el $25 \%$ son tradicionales, en el sentido aplicado aquí y el $25 \%$ son emergentes; entre los secundarios, el $17 \%$ son hombres jóvenes, el 18\%, mujeres; el resto son desocupados y jubilados. El sindicato se renueva de una forma más estable en el segmento primario; aunque los tradicionales pierden peso, son substituidos por los emergentes más acordes con la sociedad de servicios. Hay elementos comunes entre los dos tipos de afiliados que les identifican como centrales (estabilidad, negociación colectiva) y otras que son signos de la renovación, como sector económico, tipo de trabajo y profesión o nivel de estudios. Existen más dificultades para captar los grupos surgidos de la fragmentación laboral, tales como desocupados, temporales, a tiempo parcial, autoocupados; o para consolidar la afiliación de colectivos más apartados de la vida sindical y que están más afectados por los cambios de la relación laboral (jóvenes, mujeres, asalariados de la pequeña empresa...). Un 35\% de los afiliados forma parte de la periferia del mercado de trabajo, aunque con contrato estable, porque éste parece un requisito imprescindible para la afiliación; los jóvenes están en transición (tipo de estudios, categorías inferiores a las tareas que realizan), pueden llegar a sustituir a los tradicionales, por su peso en la industria, pero sus experiencias en el paro o en la precariedad dificulta el relevo generacional; las mujeres con mayor capacidad negociadora ya están entre los emergentes y, las más, están en ese $18 \%$ con rasgos ocupacionales y de trabajo periféricos que dificultan su consolidación sindical.

El estudio de CCOO de Cataluña muestra que la realidad sindical es compleja, como contradictoria es la necesidad de los trabajadores de realizar acción colectiva; un ejemplo de esto es la expresión de las demandas de los diversos colectivos afiliados (ver tabla 11). Hay dos grupos, los tradicionales y las mujeres, que centran sus demandas en el contexto o las condiciones del 
Tabla 11. Cómo, qué y a quién representa el sindicato. Una panorámica de los incentivos, demandas e intereses.

\begin{tabular}{|c|c|c|c|c|}
\hline & Tradicionales & Emergentes & Jóvenes & Mujeres \\
\hline Ideología e identidad & Elevada y homogénea & Diferenciada: identidad/eficacia & Diferenciada no formada & $\begin{array}{l}\text { Diferenciada, no formada } \\
\text { Conciencia como mujeres }\end{array}$ \\
\hline Incentivos de aproximación & $\begin{array}{l}\text { Identidad-funcional } \\
\text { Afiliación a iniciativa propia }\end{array}$ & $\begin{array}{l}\text { Funcional } \\
\text { Afiliación a iniciativa propia }\end{array}$ & $\begin{array}{l}\text { Sociabilidad } \\
\text { Afiliación por iniciativa externa }\end{array}$ & $\begin{array}{l}\text { Sociabilidad } \\
\text { Afiliación por iniciativa } \\
\text { externa }\end{array}$ \\
\hline Incentivos de afiliación & Identidad & Funcional & Material & Material \\
\hline Incentivos de permanencia & Material-identidad & Material-identidad-funcional & Material-identidad-funcional & Material-identidad-funcional \\
\hline Uso de los servicios & Menor & Menor & Mayor & Mayor \\
\hline $\begin{array}{l}\text { Antigüedad afiliativa } \\
\text { y tendencia afiliativa }\end{array}$ & $\begin{array}{l}\text { Alta } \\
\text { Decreciente }\end{array}$ & $\begin{array}{l}\text { Media } \\
\text { En aumento }\end{array}$ & $\begin{array}{l}\text { Reciente } \\
\text { En aumento (frágil) }\end{array}$ & $\begin{array}{l}\text { Media } \\
\text { En aumento (frágil) }\end{array}$ \\
\hline Responsabilidad orgánica & Alta & Media & Muy baja & Baja \\
\hline Participación & Alta & Media & Muy baja & Baja \\
\hline Principal razón no participar & Personal & Personal & \multicolumn{2}{|c|}{ El sindicato no la favorece } \\
\hline Facilidades participación & \multicolumn{4}{|c|}{ El sindicato facilita la participación y la consulta de los afiliados y trabajadores } \\
\hline Órgano de preferencia & Comité empresa-asamblea & Asamblea- sindicato & & \\
\hline Crítica orgánica & & \multicolumn{3}{|c|}{ Se tiene poco en cuenta la opinión del afiliado } \\
\hline \multirow[t]{2}{*}{ Identificación con sindicato } & $\begin{array}{l}\text { Elevada } \\
\text { (pero afiliación flotante) }\end{array}$ & Elevada & $\begin{array}{l}\text { Elevada } \\
\text { (pero afiliación entrada-salida) }\end{array}$ & $\begin{array}{l}\text { Elevada } \\
\text { (afiliación entrada-salida) }\end{array}$ \\
\hline & \multicolumn{4}{|c|}{$\begin{array}{l}\text { El sindicato resuelve problemas y los líderes sindicales merecen confianza. } \\
\text { Se identifican con los valores que defiende el sindicato y con las actividades y los servicios que ofrece }\end{array}$} \\
\hline Demandas & $\begin{array}{l}\text { Incentivos y diferencias } \\
\text { salariales } \\
\text { Precariedad, formación, } \\
\text { reciclaje }\end{array}$ & $\begin{array}{l}\text { Reducción jornada, vacaciones } \\
\text { Autonomía en el trabajo } \\
\text { Precariedad, formación, reciclaje }\end{array}$ & $\begin{array}{l}\text { Reforzar la actitud ante } \\
\text { la patronal } \\
\text { Salud laboral }\end{array}$ & \\
\hline $\begin{array}{l}\text { Tipo de acción sindical } \\
\text { practicada }\end{array}$ & $\begin{array}{l}\text { Negociación colectiva } \\
\text { y conflicto tradicional }\end{array}$ & $\begin{array}{l}\text { Nuevo encaje entre individual } \\
\text { y colectivo. Nuevas formas } \\
\text { de acción }\end{array}$ & Defensiva, con poca capacidad & $\begin{array}{l}\text { Defensiva, con poca } \\
\text { capacidad }\end{array}$ \\
\hline $\begin{array}{l}\text { Críticas objetivos acción } \\
\text { sindical }\end{array}$ & Seguridad en el trabajo & $\begin{array}{l}\text { Horas extraordinarias } \\
\text { Promoción }\end{array}$ & Promoción & $\begin{array}{l}\text { Formación profesional } \\
\text { Igualdad de oportunidades }\end{array}$ \\
\hline Problemas de futuro & Propuestas tradicionales & Dificult & de articular las nuevas demandas & \\
\hline $\begin{array}{l}\text { Valoración positiva objetivos } \\
\text { acción sindical }\end{array}$ & & & Acción contra la $\mathrm{p}$ & precariedad \\
\hline
\end{tabular}


trabajo; mejoras salariales, seguridad e higiene, contratación (estabilidad), disminución de la carga laboral (jornada, tareas). De hecho, estos grupos tienen trabajos rutinarios, de poca autonomía y poco satisfactorios en sí mismos; forman parte, los primeros, del segmento primario dependiente y, las segundas, de la periferia asalariada. Los emergentes, sin olvidar las condiciones de trabajo, apuntan sus demandas un poco más hacia el contenido laboral; acentúan la formación y la promoción, la organización del horario de trabajo, o la transformación del contenido del trabajo; sus ocupaciones permiten expectativas de mayor control; se aproximan a los segmentos primarios independientes del mercado de trabajo. El grupo de los jóvenes está en una posición intermedia, algunos se aproximan a expectativas en la línea del grupo emergente, aunque, para muchos otros, sus trabajos son de baja confianza y por ello sus demandas son más cercanas a la realidad de sus ocupaciones; su lugar es la periferia, aunque parte de ellos pueda acceder al segmento primario. Todo ello plantea al sindicato un gran reto de reordenación de sus demandas. Así, se aprecia una tímida transformación desde las clásicas cuestiones salariales, hacia los problemas de salud, la ocupación, la distribución de los tiempos y los factores que afectan al contenido de los puestos de trabajo (como su autonomía). Pero las contradicciones están muy presentes; los tradicionales sostienen reivindicaciones clásicas, mientras que los emergentes, los jóvenes o las mujeres introducen nuevas demandas. Enfrentar la precariedad choca con la defensa del puesto de trabajo; pero, junto a una diferente distribución de los tiempos de trabajo y vida, hace necesaria una acción imaginativa que, vinculando unos y otros tipos de ocupación, consiga un acceso más equilibrado. Hay ahí espacios comunes de acción, pero también falta una base real de apoyo; por ejemplo, el compromiso de jóvenes y mujeres, no sólo cuando su contrato laboral es estable, con el sindicato. La salud laboral es también importante, ahí sí que hay conexión entre tradicionales y jóvenes (trabajo industrial), pero el trabajo en los servicios de emergentes y mujeres tiene otros riesgos; además, la prevención de la salud permite introducir la acción colectiva en el centro de las políticas laborales de las empresas: la organización del trabajo y la tecnología.

Tradicionales y emergentes participan más en la vida orgánica del sindicato; los primeros, con una cultura más cercana a la identificación y los segundos, con una concepción más instrumental y algo menos participativa. Jóvenes y mujeres se integran menos; su acceso a cargos en la empresa y en el sindicato es limitado, bien por sus características ocupacionales y personales, bien por las limitaciones de la organización. La estructura de dirección del sindicato reproduce la segmentación laboral y está formada por asalariados centrales, renovados, pero conservando la estabilidad y la cualificación, muy importantes en cualquier estrategia colectiva de negociación y conflicto. Por el contrario, el acceso de los trabajadores periféricos a la responsabilidad es más complicada; aunque también hay indicios leves de renovación. Este desajuste se hace más evidente en la concepción de las estructuras de participación y de selección de las demandas, poco accesibles a éstos últimos; quizá, 
también porque su inestabilidad laboral les conduce a una búsqueda más urgente de soluciones inmediatas a sus problemas ocupacionales. Por consiguiente, otro reto para el sindicato es el cambio organizativo para adecuarse a bases más heterogéneas.

En definitiva, la identificación y el compromiso de los afiliados con el sindicato son elevados, pero existen diferencias entre segmentos, más relacionadas con el tipo de ocupación que no con la actitud hacia la organización. En este sentido, hay coincidencia con Polavieja (2003) y con Gallie (1996). El sindicato se renueva incorporando los segmentos primarios de la sociedad posindustrial (trabajo no manual, cualificado y con estudios, del sector servicios), pero es más difícil la integración de los segmentos secundarios; no tanto por factores de identidad y funcionalidad de las asociaciones, como por las demandas e intereses representados por el sindicato y por las formas de reclutamiento e integración organizativa que ofrece a los diferentes colectivos de trabajadores. Los diferenciales no son tan dramáticos como los relevados en la Alemania unificada por Streeck (2001) y, en cambio, hay una relativa coincidencia con la situación expuesta por Gallie (1996) para el sindicalismo británico. No obstante, la comparación revela algunas carencias del estudio debido a su carácter de caso específico, pero también por la escasez de estadísticas significativas sobre las relaciones laborales y la presencia sindical en España. No se trata tan sólo de comparar las actitudes y valoraciones de afiliados y no afiliados; también hay que tener en cuenta los rasgos del modelo laboral y sindical español, que inciden en diferenciales de acción de los asalariados en relación con los de otros países. La representatividad alcanzada en las elecciones sindicales (compitiendo con otros sindicatos) determina la representación colectiva en la empresa (delegados, comités) y a nivel supraempresarial (presencia en la negociación colectiva, con resultados que benefician a todos los asalariados); este modelo puede propiciar actitudes y compromisos (identidad, sociabilidad) débiles con el sindicalismo en general, mientras la decisión concreta, y temporal, de afiliarse a una u otra organización parece vincularse a la consecución eficaz y temporal de incentivos materiales o funcionales. Nuestros datos no permiten una contraposición rigurosa a la teoría de los incentivos de Olson (1992), pero sí remarcar algunos aspectos descriptivos. Los cuatro incentivos señalados inciden de manera diferente según el colectivo y según la fase de compromiso considerados (reclutamiento, afiliación, permanencia), también según el momento de expresión de la demanda (próxima o futura, o de crisis o auge de la economía) o de su traducción a una acción sindical concreta. Y, si bien la identificación con el sindicato es elevada para todos los grupos (resuelve problemas, genera confianza, promueve valores y acciones adecuados), los incentivos a afiliarse o permanecer en la organización se vinculan con los rasgos ocupacionales de los diferentes grupos y se traducen en indicadores diversos de apoyo o compromiso (antigüedad, participación y militancia en la organización). 


\section{Bibliografía}

Alós, R.; Jódar, P.; Martí, J.; Martín, A.; Miguélez, F.; Rebollo, O. (2000). La transformación del sindicato. Estudio de la afiliación de CCOO de Catalunya. Barcelona: Viena/CONC.

Braverman, H. (1975). Trabajo y capital monopolista. México: Nuestro Tiempo. BuraWOY, M. (1989). El consentimiento en la producción. Madrid: Ministerio de Trabajo y Seguridad Social.

CELlA, G.P. (1997). Le tre forme dello scambio. Bolonia: Il Mulino.

CERES (1999). Afiliació en alta a la CONC 1998. Explotació de les bases de dades d'afiliació de la CONC (mímeo).

ESCUDERO, R. (coord.) (2002). Observatorio de la negociación colectiva. Madrid: CCOO. Gallie, D.; Penn, R.; Rose, M. (1996). Trade Unionism in Recession. Oxford University Press.

GASPARINI, G. (1978). Sindacato e organizzazione. Milán: Franco Angeli.

GIDDENS, A. (1982). La estructura de clases en las sociedades avanzadas. Madrid: Alianza.

GiNTIS, H. (1983). «La naturaleza del intercambio laboral y la teoría de la producción capitalista». En TOHARIA, L. (ed.). El mercado de trabajo: teoría y aplicaciones. Madrid: Alianza.

HeCKSCHER, C. (1993). El nuevo sindicalismo. La participación del trabajador en la empresa en transformación. Madrid: Ministerio de Trabajo y Seguridad Social. Hirschman, A.O. (1977). Salida, voz y lealtad. México: Fondo de Cultura Económica. HyMAn, R. (1981). Relaciones industriales. Una introducción marxista. Barcelona: Blume.

- (1994). "Changing Trade Unions Identities and Strategies». En Hyman, R.; FERner, A. (eds.). New Frontiers in European Industrial Relations. Cambridge: Basil Blackwell.

- (1997). "Trade unions and interest representation in the context of globalisation». Transfer, vol. 3, n. ${ }^{\circ}$ 3. Bruselas: Instituto Sindical Europeo.

JÓdAR, P. (2000). "Relaciones Laborales». En BenAVIdeS, F.J.; Ruiz-FruTos, C.; GARCíA, A.M. Salud laboral. Barcelona: Masson.

KelLY, J. (1998). Rethinking industrial relations. Londres: Routledge.

LANGE, P. y otros (1991). Sindicatos, cambio y crisis. Madrid: Ministerio de Trabajo y Seguridad Social.

MarX, K. (1982). El Capital (3 vol.). México: Fondo de Cultura Económica.

Miguélez, F. (1991). "Las organizaciones sindicales». En Miguélez, F.; Prieto, C. (dirs.). Las relaciones laborales en España. Madrid: Siglo XXI.

- (1999). "Presente y futuro del sindicalismo en España». En MiguÉLEZ, F; PRIETO, C. (dirs.). Las relaciones de empleo en España. Madrid: Siglo XXI.

OfFE, C. (1984). La sociedad del trabajo. Madrid: Alianza Universidad.

Offe, C.; Wiesenthal, H. (1992). «Dos lógicas de acción colectiva». En Offe, C. (ed.). La gestión política. Madrid: Ministerio de Trabajo y Seguridad Social.

Olson, M. (1992). La lógica de la acción colectiva. México: Noriega.

Piore, M. (1983). "Notas para una teoría de la estratificación del mercado de trabajo». En TOHARIA, L. (comp.). El mercado de trabajo: teorias y aplicaciones. Madrid: Alianza.

POLANYI, K. (1989). La gran transformación. Madrid: La Piqueta.

POLAVIEJA, J.G. (2003). Estables y precarios: desregulación laboral y estructura social en España. Madrid: Centro de Investigaciones Sociológicas. 
Poole, M. (1993). Relaciones industriales: modelos y orígenes de la diversidad nacional. Madrid: Ministerio de Trabajo y Seguridad Social.

Rebollo, O.; MARTín, A.; MiguÉLEZ, F. (1993). El sindicalismo a través de sus protagonistas. Barcelona: CERES.

ReCiO, A. (1999). "La segmentación del mercado de trabajo en España». En MiguÉLEZ, F.; PRIETO, C. (eds.). Las relaciones de empleo en España. Madrid: Siglo XXI. SLOMP, H. (1998). Between bargaining and politics. Wesport: Praeger.

SORGE A.; STREECK W. (1993). «Relaciones industriales y cambio técnico: una perspectiva más amplia». En HyMAN, R.; STREECK, W. (comps.). Nuevas tecnologias y relaciones industriales. Madrid: Ministerio de Trabajo y Seguridad Social.

STREECK, W. (1978). «Processi di razionalizzazione amministrativa nei sindacati della Germania Occidentale». En GASPARINI, G. (1978). Sindacato e organizzazione. Milán: Franco Angeli.

- (2001). "High Equality, Low Activity: The Contribution of the Social Welfare System to the Stability of the German Collective Bargaining Regime». EUI Working Papers, 2001/06.

STREeCK, W.; SChMiTTER, P. (1985). "Comunità, mercato, stato e associazioni? Il possible contributo dei governi privati all'ordine sociale». Stato e Mercato, n. 13, p. 47-86.

SupIOT, A. (2001). Beyond Employment. Changes in Work and the Future of Labour Law in Europe. Oxford: Oxford University Press.

TraXLER, F. (1995). "Two Logics of Collective Action in Industrial Relations?». En Crouch, C.; TraXler, F. (eds.). Organized Industrial Relations in Europe: What Future? Aldershot: Ashgate.

VIsSER, J. (1991). «Tendances de la syndicalization». Perspectives de l'emploi. París: OCDE.

- (1994). «European Trade Unions: the Transition Years». En Hyman, R.; Ferner, A. (eds.). New Frontiers in European Industrial Relations. Cambridge: Basil Blackwell.

VALKENBURG, B.; ZOLL, R. (1995). «Modernization, individualization and solidarity: two perspectives on European Trade Unions today». European Journal of Industrial Relations, n. ${ }^{\circ} 1$.

Waddington, J.; Hoffmann, R. (2000). Trade Unions in Europe. Bruselas: ETUI. 